Nina Mazi, $d r$. medicine prometa in športa

\title{
TUDI NAŠI MOŽGANI POTREBUJEJO ENERGIJO \\ $\mathrm{Z}$ nožem in vilico namesto s svinčnikom in papirjem
}

$S_{\text {te }}$ salni mizi raje zatekli v kuhinio ali shrambo? Potem ko smo dolgo verjeli, da so možganske sposobnosti predvsem dedno pogojene - prirojene, sedaj lahko z olajšanjem ugotavljamo, da jih je mogoče izuriti, izboljšati, pomnožiti, obogatiti in oplemenititi, vplivati nanje na dokaj preprost način - ne le z disciplino in možgansko telovadbo, marveč tudi in predvsem z gurmanskimi užitki pri obloženi mizi. Seveda mora biti njena vsebina skrbno izbrana, odmerjena in preverjena, pa vendar. Inteligenčni kvocient je po najnovejših

Ni useeno kakšno hrano dobivajo naši možgani. ugotovitvah mogoče ohranjati in dvigniti $z$ ustrezno hrano in pijačo (ki vplivata tudi na IQ).

Hitrost mišljenja, sposobnost koncentracije, zanesljivost spomina in celo moč ustvarjalnosti je mogoče uravnavati $z$ vilico in nožem. Senzacionalno odkritje, ki stopa ob bok že znanemu dejstvu, da hrana močno vpliva na čustva, občutke, razpoloženje in psihično počutje. Strokovnjaki so v visokospecializiranih biotehnoloških laboratorijih ugotovili, da orehi spodbujajo modrost, ingver krepi ustvarjalnost, kumina spodbuja bliskovitost mišljenja in humor, banana dviguje razpoloženje, ananas pa spodbuja komunikacijske sposobnosti - zlasti verbalne funkcije.

\section{PROCESI V OSRČJU ČLOVEŠKIH MOŽGANOV}

V centralnem živčnem sistemu (predvsem njegovem osrednjem, kefalnem delu) več kot 100 milijard živčnih celic (nevronov) od rojstva (faze nosečnosti, v kateri se izoblikujejo možgani) do smrti nepretrgoma opravlja težko, zahtevno in odgovorno delo (neki zdravnik je $v$. šali dejal, da sta srce in glava največja garača $v$ organizmu, saj si tudi takrat, kadar človek ne razmišlja kdo ve kako intenzivno in ni na sveže zaljubljen, ne smeta privoščiti brezkompromisnega počitka).

Vsak nevron je z živčnimi vlakni (nevriti) preko živčnih sklopov (sinaps) in nevrotransmitornih substanc povezan $\mathrm{z}$ ostalimi živčnimi celicami v visokospecializirano, izredno fleksibilno in sila občutljivo mrežo nevronov (nekakšno možgansko integrirano vezje). Med osrednjim živčevjem (možgani) in zunanjim svetom se preko čutil in živčnih končičev vsako sekundo izmenja več milijonov informacij. Za svoj obstoj in delovanje potrebujejo male sive celice možganskega tkiva precej energije, biokemijskega oziroma električnega naboja in vitalnosti. Tako na možgane, ki predstavljajo le 2-3 odstotke telesne teže (okrog 1500 gramov), odpade kar 20 odstotkov dnevne energetske bilance. Potrebne kalorije in vitalne snovi pa tako kot drugi organi in organski sistemi črpajo iz hrane, ki jo posameznik zaužije. Ker je centralni živ- 
čni sistem dokaj občutljiv in izbirčen del organizma, seveda ni vseeno, kaj, kdaj, kako, koliko in zakaj jemo. Zlasti pomembna je obilnost in vsebina človekovega vsakdanjega jedilnika (ne tisto, kar sem ter tja pokusimo ali si privoščimo v " pregrešnih « količinah, marveč tisto, kar nenehno uživamo. Hrana, ki jo jemo iz dneva $v$ dan, odločilno pripomore $\mathrm{k}$ izboljšanju možganskega potenciala in sposobnosti malih sivih celic). Nekatera živila spodbudno vplivajo na dojemljivost, sposobnost učenja, mišljenja, pomnjenja, logičnega sklepanja, hitrega rezoniranja in jačajo koncentracijo, druga spet dvigujejo voljo, elan in razpoloženje, tretja spodbujajo optimizem in navdušenje itd.

Odkrivanje skrivnostnega sveta babičine kuhinje in potovanje $\mathrm{v}$ kulinarično zakladnico je človeka vedno navdajalo z občutkom čarobne skrivnostnosti (nič čudnega torej, da se večina izmed nas razneži ob jedeh, ki so prijetno dišale iz babičine kuhinje, ter se ne more upreti hrani, ki jo je mojstrsko pripravljala mama).

O vplivu hrane na duševnost priča tudi dejstvo, da je znani nemški filozof že pred dobrima dvema stoletjema, ko se ljudem sploh še ni sanjalo o delovanju hrane na čustva in IQ, izjavil, da je dobra hrana zanj vir telesnega ugodja in intelektualnega užitka. Zanimivo je tudi, da večina ljudi kupuje kuharske knjige predvsem zato, da jih prelistava, prebira in pregleduje, morda celo študira in analizira. Ob tem pa sanjari, se predaja nostalgičnim spominom, razmišlja, si buri domišljijo in si krepi ustvarjalnost. Ko so enega največjih pravljičarjev vseh časov, Hansa Christiana Andersena, vprašali, kako je zadovoljen s svojim pisateljevanjem in kaj si želi še ustvariti, je z nagajivo iskrico $\mathrm{v}$ očeh navdušeno izjavil, da bi rad napisal pravljično kuharico $\mathrm{z}$ recepti svoje pokojne babice.

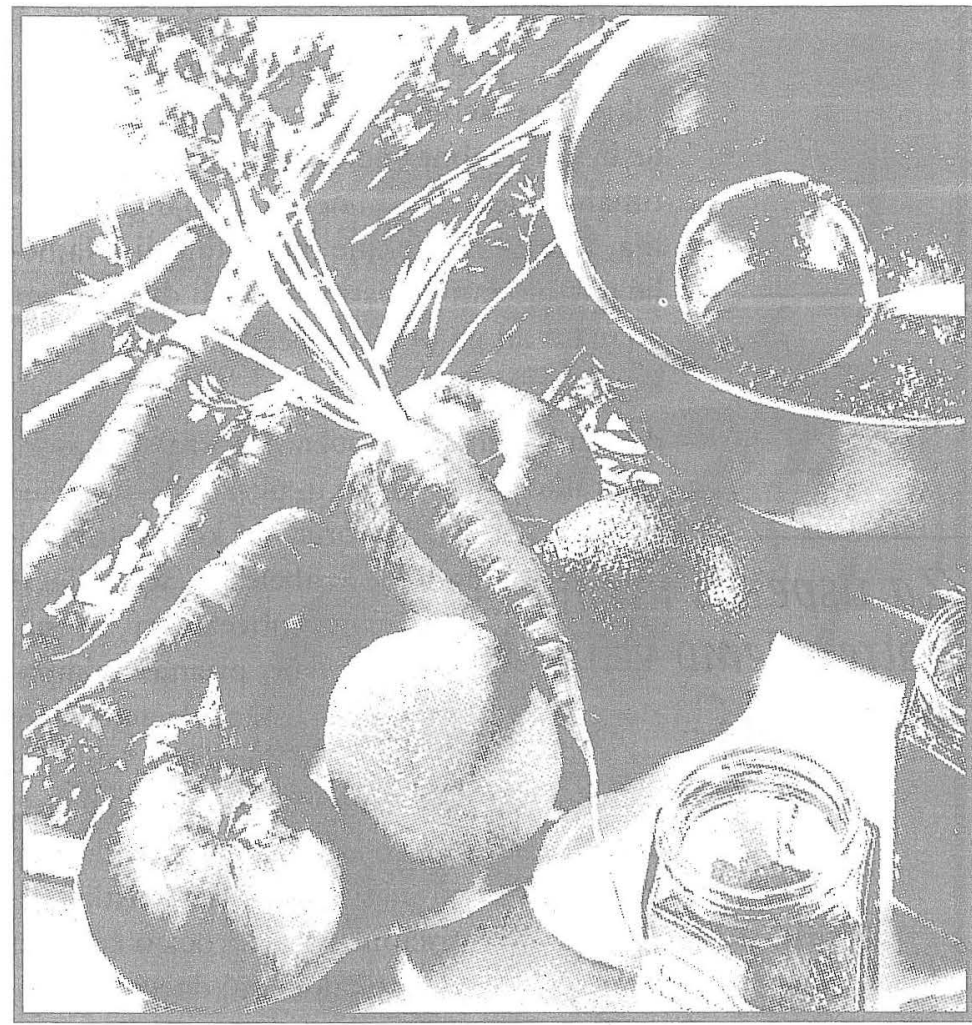

\section{KATERA HRANA NAJBOLJ PRIIJA NAŠIM MOŽGANOM?}

Paleta »intelektualnih « živil je pestra in zanimiva, optimalen izbor pa je seveda odvisen predvsem od lastnosti in sposobnosti centralnega živčnega sistema, ki bi jih radi okrepili, poudarili, izboljšali, osvežili in izurili.

\section{Mišljenje}

Korenje, ki pripomore $\mathrm{k}$ izboljšanju spominskih sposobnosti, je prava poslastica za pozabljivce. Pospešuje učenje na pamet - pomnjenje in reproduciranje naučene snovi, s tem da spodbuja presnovo v možganih. Pred učenjem pesmice, matematičnih formul ali angleškega slovarja si velja torej privoščiti skledico kuhanega korenja z olivnim oljem (lahko tudi s kislo smetano ali žličko masla).

Ananas, sladek tropski sadež, upravičeno velja za najbolj priljubljeno sadje igralcev, recitatorjev in glasbenikov. Kdor se želi us- 
pešno učiti in dobro naučiti dolge tekste ali skladbe, potrebuje veliko vitamina $C$. Hkrati pa vsebuje ananas tudi druge vitamine in pomembne encime $\mathrm{v}$ kombinaciji $\mathrm{z}$ optimalno mešanico mineralov (mangana, kalija, železa) in vsebuje malo kalorij. Najbolje je vsak dan pojesti rezino ali dve svežega ananasa ali pa popiti 2 decilitra soka iz svežega sadeža.

Avokado velja med poznavalci za specialista za kratkoročni spomin in bliskovito mišljenje (memoriranje konceptov, pi-

Za uspešno učenje potrebujemo veliko vitamina $\mathrm{C}$. sanje zabeležk, sestavljanje seznama obveznosti za naslednji dan, pisanje nakupovalnega listka, memoriranje telefonske številke - lahko jo nekajkrat zavrtimo, ne da bi si jo morali pred tem zapisati), svojo učinkovitost pa dolguje visoki vsebnosti maščobnih kislin rastlinskega izvora. Nutricionisti priporočajo četrt do pol avokada (visokokaloričen) dnevno.

Kosmulje, rumeno-rjavkaste jagode, sorodnice črnega ribeza, so z bogastvom vitaminov (C, A, B in D), mineralov (kalij, kalcij, fosfor), sadnih sladkorjev in kislin ter rastlinskih vlaknin pri minimalni energetski obremenitvi (17 kcal/100g) prav tako koristne za možgane.

\section{Zadovoljstvo, optimistično razpoloženje in sreča}

Čokolada, katere učinek je sicer res kratkotrajen, zato pa toliko bolj intenziven, spodbuja hormon sreče, serotonin. Nič čudnega, da nerazpoloženi posamezniki in depresivci tako radi segajo po njej. Mnogi postanejo z njo celo zasvojeni in se uvrstijo med čokoholike, pogosto pa tudi med debeluščke.

Paprika spodbuja izločanje endogenih opiatov, kot sta serotonin in endorfin (hormona sreče). Bolj ko je ostra in pekoča, bolj je učinkovita. Priporočljivo jo je uživati surovo z oljem ali smetano.
Jagode so sadje za študente, raziskovalce, profesorje in vse, ki morajo delati predvsem z glavo. Olajšajo premagovanje stresa ter sprožajo občutek lahkotnosti in dobrega razpoloženja. Optimalna dnevna doza je okrog 150 gramov svežih jagod (lahko tudi brez sladkorja in stepene smetane).

Banane upravičeno veljajo za zlato sadje. Bogate so s serotoninom - substanco, ki spodbuja možgane, da človeka navdajo z občutkom sreče. Ponašajo se $\mathrm{z}$ obilico vitaminov (skupine B in C), mineralov (kalij, kalcij, železo), balastnimi snovmi (vlaknine) in lahko prebavljivimi kompleksnimi ogljikovimi hidrati (polnovrednimi sadnimi sladkorji).

\section{Učenje}

Zelje in ohrovt preprečujeta nemir in nervozo (regulirata in upočasnita delovanje ščitnice). Učenje je bolj učinkovito in sproščeno (premagovanje napetosti, stresa in treme pred izpiti, zagovori, predstavitvami, nastopi $\mathrm{v}$ javnosti in pomembnimi preizkušnjami).

Limone (agrumi) z zavidljivo zalogo askorbinske kisline in minimalnim številom kalorij človeku pomagajo, da postane in ostane svež, čil in vitalen - dojemljiv za dražljaje iz okolja, dovzeten za podatke in sprejemljiv za informacije. Pred jezikovnim testom si privoščite razkošje svežega koktejla iz agrumov (limona, grenivka, pomelo, limončelo, pomaranča, mandarina).

Borovnice priporočamo kot osvežilni sadni prigrizek v premorih med dolgotrajnim učenjem. Spodbujajo centralno cirkulacijo (prekrvavitev možganov). Najboljše so sveže, lahko z dodatkom limone, sladkorja, smetane, v obliki pireja, z jogurtom, v obliki gostega nerazredčenega soka ali mlečnega napitka.

\section{Spomin}

Peteršilj pomaga pri tvorjenju engramov. Bogat je $\mathrm{z}$ vitaminom $\mathrm{C}$, beta-karotenom in 
folno kislino, minerali, encimi, vlakninami in biološko aktivnimi varovalnimi snovmi. Pospešuje presnovo in prekrvavitev osrednjega živčevja, nevtralizira škodljive proste radikale (upočasni degeneracijo možganov) in preprečuje arteriosklerozo (zaplete $\mathrm{z}$ ožiljem v možganih). Priporočljiv je surov (žvečenje vejic svežega peteršilja), kot dodatek jedem (mesu, ribam ...) ali kot čaj (10 vejic peteršilja prelijte $\mathrm{z}$ veliko skodelico vrele vode, pustite stati 10 minut, osladite z medom in dodajte limonin sok). Pijte trikrat dnevno $\mathrm{v}$ fazi intenzivnega učenja in študija.

Ribe (tuna, losos, sardine) in morski sadeži (ostrige) so bogati z vitamini (D, E, A), minerali (jod, kalcij, železo) in organizmu prijaznimi nenasičenimi maščobnimi kislinami omega-3, ki spodbujajo tvorbo povezav (sinaps) med sivimi možganskimi celicami in tako spodbujajo shranjevanje informacij ter sprejetih spominskih zapisov. Obenem omogočajo tudi ažuriranje shranjenega spominskega gradiva in njegovo hitro uporabnost $\mathrm{v}$ danem trenutku.

Jabolka so pravi eliksir za možgane. Spodbujajo presnovo in delovanje ter preprečujejo staranje, obolevanje in propadanje možganskih celic (nevronov). Bogata so z vitamini ( $\mathrm{A}$ in $\mathrm{C}$ ), minerali, pektini in vlakninami.

Mango je bogat $\mathrm{z}$ vitaminom $\mathrm{C}$ in betakarotenom, vlakninami in encimi, izboljšuje oskrbo možganskega tkiva s kisikom in hranili, preprečuje motnje prekrvavitve in presnove, poškodbe in prehitro propadanje malih sivih vragcev v centralnem živčnem sistemu. Spodbuja spominske funkcije možganov tako, da krepi dolgo- in kratkoročni spomin.

\section{Koncentracija}

Škampi sodijo med žlahtno hrano za možgane. Telesu dovajajo življenjsko pomembne nenasičene omega-3 maščobne kisline in pomagajo $\mathrm{k}$ dalj časa trajajoči pozornosti in

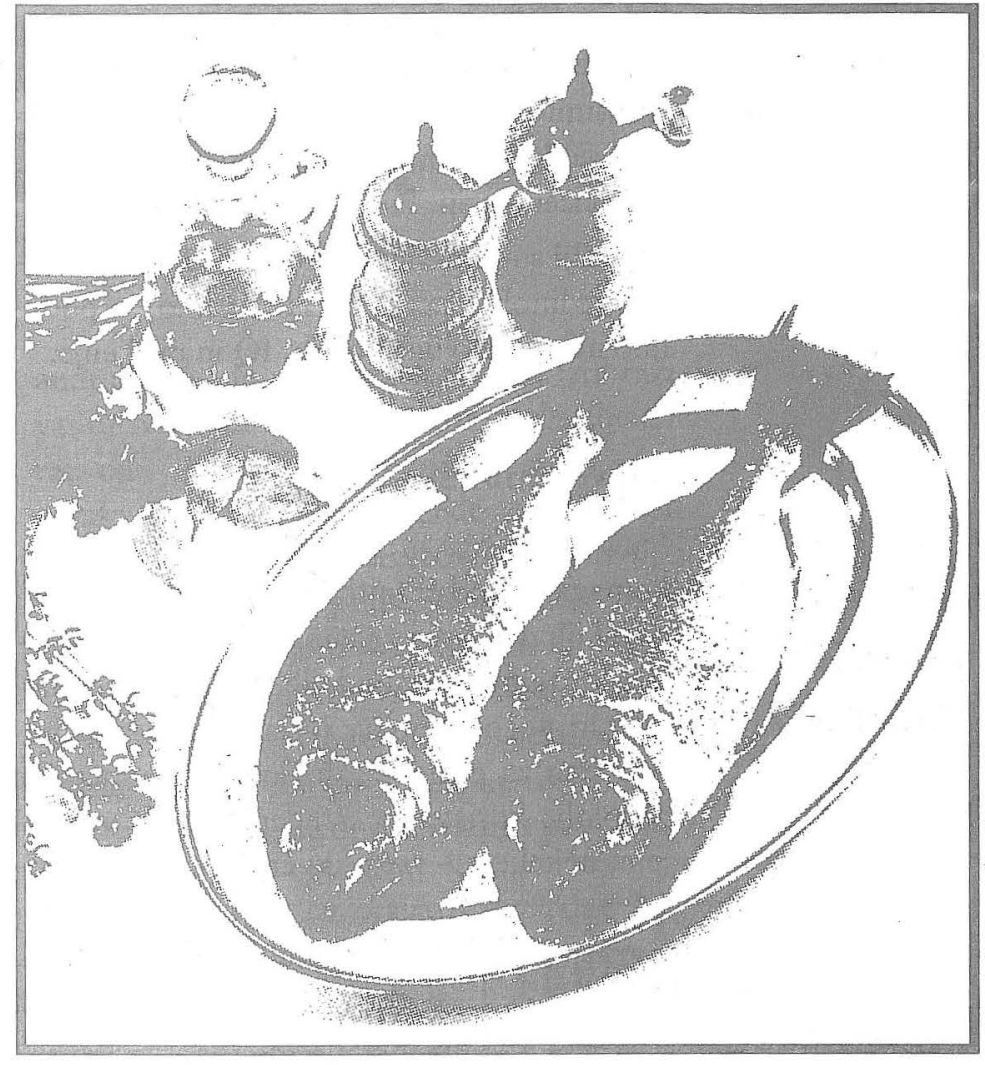

globlji koncentraciji. Zadostuje jih 100 gramov dnevno. Pri pripravi ne pozabite drobnega, a pomembnega trika kuharskih mojstrov - solite jih, tik preden jih servirate (že pečene, dušene ali ocvrte, redkeje kuhane).

Čebula je kot preprosta povrtnina sila cenjena v možganskih sferah. Priporočljiva je pri obremenitvah (napetost, preobremenjenost in stres), psihični utrujenosti, psihofizični blokadi in naveličanosti. Čebula redči kri, izboljšuje oskrbo možganov s kisikom in hranilnimi snovmi. Optimalna doza: vsaj polovico čebule (najbolje surove $\mathrm{z}$ olivnim oljem) dnevno.

Orehi veljajo za najboljše živilo oziroma posladek intelektualnih maratoncev (simpoziji, predavanja, klasične in telekonference, predstavitve, zahtevni brainstormingi, dolge in naporne vožnje $z$ avtomobilom). Bogati so $\mathrm{z}$ mononenasičenimi rastlinskimi maščobami, vitamini (zlasti E), minerali (kalcij), 
balastnimi in varovalnimi snovmi. Krepijo ožilje in živčevje, spodbujajo tvorbo nevrotransmitornih substanc $\mathrm{v}$ možganih in pomagajo $\mathrm{k}$ boljšemu razumevanju, dojemanju in koncentraciji. Pozor: energetska bomba.

Mandlji so podobni orehom, dodatno vsebujejo še linolno in linolensko kislino, in podobno učinkujejo na spomin, IQ in mišljenje.

\section{Ustvarjalnost}

Ingver sprošča in razbremenjuje možgane. Pomaga jim odstraniti nepotreben balast, napravi jih dovzetne za zunanje dražljaje in notranje vzgibe. Spodbudi jih k novim, originalnim in neponovljivim idejam. Ingver je pomemben za pisatelje, novinarje in umetnike nasploh, koristen je študentom, menedžerjem, učiteljem - vsem, ki črtijo rutino in pri-

\section{Pravilna prehrana} je še zlasti pomembna $v$ stresnih situacijah. segajo na ustvarjalnost. Uživamo ga lahko kot začimbo, dodatek jedem (sladicam) in v obliki čaja.

Kumina naj bi po mnenju ameriških znanstvenikov spodbujala ustvarjalnost pri otrocih. Dojenčki s prebavnimi motnjami, ki so v najnežnejšem otroštvu uživali znatne količine kuminovega čaja, so se kasneje izkazali z boljšo domišljijo in večjo ustvarjalnostjo. Tudi pri odraslih naj bi sproščala znamenite prebliske in ustvarjalne trenutke. Eterično olje kumine spodbuja delovanje živčevja in možganov. Kdor potrebuje dobre ideje, zavrača kalupe in rutino ter se želi v življenju zabavati in domiselno kratkočasiti, naj bi redno užival čaj iz aromatičnih semen kumine. Recept: dve čajni žlički zdrobljenih semen kumine na skodelico vrele vode.

Preobremenjenost, napetost in stres upočasnjujejo in zavirajo mišljenje ter sčasoma celo znižajo IQ. Zato poskrbite, da boste v zahtevnih in kriznih obdobjih uživali hrano, s pomočjo katere se boste lažje upirali stresu. $\mathrm{Na}$ jedilnik uvrstite predvsem živila, bogata z vitamini skupine $\mathrm{B}, \mathrm{C}, \mathrm{A}$ in $\mathrm{E}$, selenom, magnezijem in kalcijem (sadje, zelenjava, polnovredne žitarice in stročnice, ribe ipd.). $\mathrm{Ne}$ pretiravajte $\mathrm{z}$ maščobami, privoščite si zmerno dozo beljakovin in zvrhano mero ogljikovih hidratov. Slednji so v času stresa pomembni, ker organizmu zagotavljajo hitro dozo potrebne energije, $s$ pomočjo katere prizadeti lažje obvladuje situacijo in premaguje stresne momente. Obenem pa rezultati najnovejših znanstvenih raziskav potrjujejo, da organizem ogljikove hidrate smotrno uporabi za sintezo antistresnih substanc, ki v možganih zmanjšujejo učinke stresa in preprečujejo njihov škodljiv vpliv na telo in dušo.

Ko boste naslednjič pred učenjem, po njem ali med njim (morda celo namesto njega) sedli k mizi, razgrnili prtič in segli po priboru, preverite, ali je na jedilniku, ki ste ga izbrali oziroma vam ga ponujajo, vsaj nekaj živil, namenjenih spodbujanju in ohranjanju intelektualnih funkcij. In ne pozabite: učni uspeh se rojeva tudi v kuhinji.

\section{LITERATURA}

Bambecks, Joern J., Wolters, Antje, 1995, Moč možganov - Kako izboljšamo svoje umske zmožnosti, Sledi, Žalec

Bean, Anita, 1998, Food for Fitness, A\&C Black, London.

Beaver, Diana, 1995, Krog odličnosti, Julija Pergar, Ljubljana.

Burns, David D., 1998, Kako smo lahko srečni in zadovoljni, Mladinska knjiga, Ljubljana.

Chichester, Brian, 1998, Natural healing Secrets, Random House Value Publishing, Inc, New York, USA.

Golemen, Daniel, 1996, Emotional Inteligence, Bloomsbury Publishing, London.

Hanson, Peter G., 1994, The Joy of Stress, Andrews and McMeel, Kansas City, USA.

Mayhew Maggie, Whiteman Kate, 1998, The World Encyclopedia of Fruit, Anness Publishing, Ltd, London.

Mindell, Earl, 1998, Hrana kot zdravilo, Mladinska knjiga, Ljubljana.

Sveta Hildegarda, 1998, O zdravem prehranjevanju, Mladinska knjiga, Ljubljana. 